Article

\title{
Corrosion of $\alpha$-Brass in Solutions Containing Chloride Ions and 3-Mercaptoalkyl-5-amino-1H-1,2,4-triazoles
}

\author{
Oleg Kozaderov ${ }^{1}$, Khidmet Shikhaliev ${ }^{1}$, Chetti Prabhakar ${ }^{2}{ }^{\circledR}$, Anuj Tripathi ${ }^{2}$, \\ Dmitry Shevtsov ${ }^{1, *(\mathbb{D}}$, Alexei Kruzhilin ${ }^{1}$, Ekaterina Komarova ${ }^{1}$, Andrei Potapov ${ }^{1}{ }^{(D)}$, \\ Ilya Zartsyn ${ }^{1}$ and Yuri Kuznetsov ${ }^{3}$ \\ Faculty of Chemistry, Voronezh State University, Universitetskaya pl. 1, 394018 Voronezh, Russia \\ 2 Department of Chemistry, National Institute of Technology, Kurukshetra 136119, Haryana, India \\ 3 Laboratory of Physico-Chemical Fundamentals of Corrosion Inhibition of Metals and Alloys, A.N. Frumkin \\ Institute of Physical Chemistry and Electrochemistry, Russian Academy of Sciences, (IPCE RAS), 31 Leninski \\ Prospect, 119071 Moscow, Russia \\ * Correspondence: shevtsov@chem.vsu.ru
}

Received: 14 June 2019; Accepted: 10 July 2019; Published: 15 July 2019

check for updates

\begin{abstract}
The protective effect of 3-mercaptoalkyl derivatives of 5-amino-1H-1,2,4-triazole against corrosion of $\alpha$-brass in a chloride media was studied using polarization curves, electrochemical impedance spectroscopy, and full-scale corrosion testing. The brass electrode remains passive up to the activation potential, which is much higher than in solutions without organic additives, and it increases with the concentration of the inhibitor. The protection degree of all the studied inhibitors reaches its maximum of over $99 \%$ in solutions with the concentration of the inhibitor $C_{\text {inh }} \geq 0.10 \mathrm{mM}$. The protective effect increases with the length of the alkyl chain. All the studied derivatives are effective against atmospheric corrosion of $\alpha$-brass. A protective film is formed on the brass surface, and it most probably includes oxides as well as complex compounds of zinc and copper with the molecules of the inhibitors. The impedance spectroscopy demonstrated that the presence of the inhibitor results in a decrease in the double-layer capacitance and an increase in the polarization resistance, which proves that the protective film actually forms on the brass surface. The quantum chemical analysis of the optimized molecular structures demonstrates that all the studied inhibitors should have a similar protective effect, which agrees with the experimental results.
\end{abstract}

Keywords: brass; chloride; triazole derivatives

\section{Introduction}

Due to their high thermal conductivity, workability, and low cost, copper and copper-based alloys are widely used in heat-exchange equipment. Brasses, which are alloys of copper and zinc, are relatively harder and stronger, but are prone to corrosion in aggressive environments. Apart from the uniform attack, the most common forms of brass corrosion are selective leaching (dezincification) [1], stress-corrosion cracking [2,3], and pitting. Selective leaching goes significantly faster in hydrochloric acid solutions, the rate of dezincification increases at higher temperatures [4]. In neutral chloride solutions, selective leaching occurs during the early stages of the corrosion process [5]. Corrosion models [6] demonstrate that, during selective leaching in brasses, zinc anodically dissolves, and as a result, vacancies and copper adatoms appear on the surface of the alloy. By means of surface diffusion, they form a highly developed phase characterised by the increased thermodynamic activity of copper [7]. Consequently, the corrosion of brasses becomes pseudo-selective, as both components are ionized followed by the deposition of copper [8-10]. As opposed to brass corrosion in an acidic environment, 
when the ionization/deposition results in the formation of a sponge Cu-metal, neutral chloride solutions produce additional multiple surface layers containing oxides of zinc and copper [11-13]. According to $[5,14-16]$, the formation of such layers from $\mathrm{ZnO} \times \mathrm{H}_{2} \mathrm{O}, \mathrm{Cu}_{2} \mathrm{O}$, and $\mathrm{CuO}$ passivate the surface of $\alpha$ - and $\beta$-brasses in buffer chloride solutions and promotes corrosion resistance. According to [17], the sublayer resulting from dezincification is rich in corrosion-resistant copper, which also contributes to the protective effect. This sublayer, however, appears due to the sparingly soluble multicomponent structure formed when alloys are kept in alkali-chloride solutions for a long time. It is this structure that effectively protects the material from corrosion attacks when the concentration of chloride ions is relatively low, with $\mathrm{CuCl}$ providing additional protection [18]. When the chloride concentration reaches a certain critical point, the rate of corrosion increases dramatically due to the formation of soluble $\mathrm{CuCl}_{2}$ - and discontinuity of the passive film. Compared to pure copper, brasses are much more prone to pitting, as the multicomponent surface layer containing $\mathrm{ZnO}$ is less resistant to dissolution in a corrosive environment [14,15]. In the presence of chloride ions, dezincification and localized attacks on the surface of $\alpha$-brass take place simultaneously [19], which adds to the corrosive effect.

Authors [1] suggests deoxygenation of solutions, anodic protection, and doping as methods of protection of brasses from selective leaching. These methods, however, have a number of drawbacks. Namely, they require constantly low concentrations of dissolved oxygen, additional sacrificial materials, or changing the composition of the copper-zinc alloy. These obstacles can be avoided by using inhibitors, which is quite a common technique to control corrosion of copper and its alloys in water solutions [20-23]. The protective effect is found in organic compounds containing heteroatoms of nitrogen, sulphur, phosphorus, and oxygen, polar groups, heterocycles, and benzene rings with delocalized $\pi$-electrons [24-29].

There are quite a number of substances that produce an anti-corrosion effect on brasses. Thus, quinoline derivatives are effectively adsorbed on $\alpha$-brass in an acid environment [30], while aminopropanol derivatives do so in neutral chloride solutions [31]. Diphenylamine derivatives form thin protective films [32], and phenol derivatives produce self-organizing layers on copper-zinc alloys [33]. However, the most effective corrosion inhibitors proved to be derivatives of azoles, widely used to control corrosion of copper, the main component of brasses [34-40]. Thus, adding 1,2,3-benzotriazole (BTA), benzimidazole, pyrazole, or their derivatives to a corrosive environment, including a chloride environment, results in the formation of a chemisorptive compound [41] or a multicomponent structure on brass, which, besides copper and zinc oxides, includes polymer systems with ions $\mathrm{Cu}(\mathrm{I})$ and $\mathrm{Zn}$ (II) [42-51]. This creates a protective barrier for both metal components of the copper-zinc alloy and prevents further oxidation and consequent dezincification and pitting of brass.

BTA is known to be toxic [52-54], so various organic and inorganic compounds may be considered as alternatives. It was found, however, that sodium salt of glycogenic and polyphosphoric acids [55], as well as chromates, molybdates, tetraborate, tungstates [56,57], and natural aragonite [58], whose corrosion protection properties were studied, do not protect brasses as effectively as the derivatives of environmentally friendly 1,2,4-triazole. Thus, the degree of protection of $\alpha$-brass in hydrochloric acid solutions with 5-amino-1H-1,2,4-triazole is up to $96 \%$ [59]. The effect is accounted for by the formation of a barrier layer that includes aminotriazole-copper systems and a copper oxide (I).

For neutral chloride solutions, 3-amino-1,2,4-triazole is highly effective, with the $\mathrm{Cu}-40 \mathrm{Zn}$ brass corrosion inhibition effect increasing in the presence of sulphides [60] or if the inhibitor is polymerized [61]. The inhibition effect of azoles derivatives can be improved by introducing additional heteroatoms, such as $\mathrm{S}$, in the structure of the inhibitor. Taking into account that mercapto derivatives of azoles are biodegradable, they seem to be the most effective and environmentally friendly corrosion inhibitors for brasses.

Their effectiveness against corrosion of copper in a neutral chloride environment was demonstrated in experiments with 2-mercaptobenzimidazole [62,63], 2-mercaptobenzoxazole [64], and 2-mercaptobenzothiazole [65]. Reference [66] demonstrates that mono- and poly-molecular chemisorption of 5-alkylmercapto-3-amino-1,2,4-triazoles on an oxidised Cu-electrode passivate 
copper very effectively. The protective effect of 5-alkylmercapto-3-amino-1,2,4-triazoles in a neutral chloride-borate buffer solution is most probably accounted for by the adsorption of the inhibitor from the solution and the formation of a protective nano-layer of sparingly soluble complex compounds, both on copper [67] and on $\mathrm{Cu}-20 \mathrm{Zn}$ brass [68]. The critical role of the complex formation in the passivation of $\mathrm{Cu}-20 \mathrm{Zn}$ brass in solutions containing various aggressive anions and a 2-mercaptobenzothiazole additive was proved in [69].

The purpose of the paper is to study the corrosion inhibition effect of 3-mercaptoalkyl derivatives of 5-amino- $1 H$-1,2,4-triazole on $\alpha$-brass in chloride environments using polarization curves, electrochemical impedance spectroscopy, full-scale corrosion testing, and quantum chemical simulation.

\section{Materials and Methods}

Electrochemical measurements were performed at room temperature $\left(\sim 25^{\circ} \mathrm{C}\right)$ on brass $(\mathrm{Cu} / \mathrm{Zn}$ : 63/37) electrodes in an unstirred borate buffer water solution ( $\mathrm{pH} 7.4$ ) with natural aeration, in the presence of the inhibitor and $10 \mathrm{mM} \mathrm{NaCl}$. A classical electrolytic three-electrode cell with unseparated electrode spaces was used in order to accelerate transient measurements. Derivatives of 5-amino-1H-1,2,4-triazole synthesised at Voronezh State University were used. Their names, structures, and solubility in water are given in Table 1.

Table 1. Inhibitor names, structures and solubility in water.

\begin{tabular}{cll}
\hline Symbol & Name \\
\hline 3 & 3-mercaptopropyl-5-amino-1H-1,2,4-triazole \\
$\mathrm{C} \quad$ 3-mercapto(3-methylbutyl)-5-amino-1H-1,2,4-triazole & Solubility \\
$\mathrm{C}$
\end{tabular}

The saturated silver chloride reference electrode was placed in a separate container connected to the electrolytic cell by an agar-agar based salt bridge and filled with potassium nitrate saturated solution. The auxiliary electrode was a platinum grid. The working brass electrode was polished by K3000 sandpaper, degreased in $96 \%$ ethanol, and washed with distilled water. The potentials of the working electrode $(E)$ are given according to the standard hydrogen electrode (SHE) scale. The current density $i$ was calculated by dividing the actual current $I$ by the geometric area of the working electrode $\left(2.25 \mathrm{~cm}^{2}\right)$.

Electrochemical measurements were performed using IPC-PRO potentiostat. In order to remove the oxide film appearing in air, the working $\mathrm{Cu}$-electrode was polarized at $E=-0.60 \mathrm{~V}$ for $15 \mathrm{~min}$ prior to the experiment. The electrode was then held in the solution for about 3 to 5 min until the stable free corrosion potential $\left(E_{\text {corr }}\right)$ established. The working solution was then mixed with an $\mathrm{NaCl}$ solution while stirring, so that the concentration of chloride ions would be $C_{\mathrm{Cl}}{ }^{-}=10 \mathrm{mM}$. The studied inhibitors were also added to the solution in the concentration of $C_{\text {inh }}=0.01,0.10$, and $1.00 \mathrm{mM}$. After the new $E_{\text {corr }}$ value was established, the $I, E$ polarization curve was registered by scanning the potential towards either the anodic or the cathodic direction at $0.2 \mathrm{mV} / \mathrm{s}$. Pitting potential $\left(E_{\mathrm{pit}}\right)$ was identified by the rapid increase in the current on the anodic polarization curve. Pits were then visually identified on the surface of the electrode. The measurement error for $E_{\text {pit }}$ was below $0.03 \mathrm{~V}$.

The rate of corrosion in current units $\left(i_{\text {corr }}\right)$ was determined by the polarization resistance technique as summarized by Mansfeld [70,71]. The polarization curve was previously registered by scanning the potential from $E=E_{\text {corr }}-0.03 \mathrm{~V}$ to $E=E_{\text {corr }}+0.03 \mathrm{~V}$ at $0.2 \mathrm{mV} / \mathrm{s}$. The polarization resistance $R_{\mathrm{p}}$ was 
then calculated as the slope of the polarization curve, replotted in $\Delta E, i$-coordinates ( $\Delta E=E-E_{\text {corr }}$ ), at $E_{\text {corr. }}$. The polarization curve was then plotted in coordinates $2.3 \cdot R_{\mathrm{p}} \cdot i-\Delta E$, and the Tafel slopes of the half-reaction on the anode $b_{a}$ and the cathode $b_{c}$ were determined by means of the TableCurve software as the approximation parameter of the equation $2.3 \cdot R_{\mathrm{p}} \cdot i=\frac{b_{\mathrm{a}} \cdot b_{\mathrm{c}}}{b_{\mathrm{a}}+b_{\mathrm{c}}}\left[\exp \left(\frac{\Delta E}{b_{\mathrm{a}}^{\prime}}\right)-\exp \left(\frac{\Delta E}{b_{\mathrm{c}}^{\prime}}\right)\right]$, which at $\Delta E=0$ gives $i_{\text {corr }}$. The measurements were performed at least 5 times for each of the studied concentrations of the inhibitor until the reproducible data was obtained. The data was then statistically analysed.

The effectiveness of the inhibition activity of the derivatives of 5-amino- $1 H-1,2,4$-triazole was evaluated judging by the protection level:

$$
Z_{\mathrm{i}}=\frac{i_{\text {corr }, 0}-i_{\text {corr, inh }}}{i_{\text {corr }, 0}} \cdot 100 \%
$$

where $i_{\text {corr, } 0}$ and $i_{\text {corr,inh }}$ are the corrosion current density with, and without, the inhibitor, respectively.

The electrochemical impedance spectroscopy (EIS) was performed using the IPC-PRO potentiostat with a frequency response analyser FRA-2. After $E_{\text {corr }}$ was stable for $30 \mathrm{~min}$, the frequency dependent impedance was registered within the range from 0.1 to $5000 \mathrm{~Hz}$ with no current. The results were presented as a Nyquist diagram. The analysis of the obtained results, the selection of the equivalent circuit, and determining its component values was carried out using DCS software.

Atmospheric corrosion of brass was accelerated by means of salt spray testing in order to determine the inhibition effect of derivatives of 5-amino- $1 \mathrm{H}-1,2,4$-triazole for inter-operational protection of brass products. The experiments were carried out on brass plates with the surface area $S=20 \times 50 \mathrm{~mm}^{2}$ and the thickness $d=1.00 \mathrm{~mm}$, which were previously polished by K3000 sandpaper and degreased in acetone. The protective inhibitor films were obtained by holding the brass plates in a water solution with the inhibitor for $60 \mathrm{~min}$ at $60{ }^{\circ} \mathrm{C}$. The samples were dried and placed in the cabin at $95-100 \%$ air humidity. A $5 \%$ solution of $\mathrm{NaCl}$ (pH $6.5 \div 7.2$, GOST R 52763-2007) was sprayed into the cabin every hour. The samples were examined 3 times every $24 \mathrm{~h}$ in order to register the moment $\left(\tau_{\text {corr }}\right)$ of appearance of the first signs of corrosion attack.

For microscopic analysis of the surface, a Jeol JSM-680LV scanning electron microscope (Japan) was used together with Oxford Instrument INCA 250 X-ray microanalysis module (UK) which determines the chemical composition of the surface layer.

Computational methodology was as follows. All the three molecules are fully optimized using density functional theory (DFT) with B3LYP functional at 6-311 + G (d,p) basis set in the program Gaussian 16 [72]. These optimized structures have no imaginary frequencies and hence are situated at the lowest energy of the potential energy surface. The theoretical calculation also involves determining HOMO and LUMO energies, and the energy gap along with ionization potential, electron affinity, electronegativity $(\chi)$, absolute hardness $(\eta)$, and softness $(\sigma)$ for all the molecules.

Following the density functional theory, the $\eta$ is defined as [73]:

$$
\eta=\frac{1}{2} \frac{\partial \mu}{\partial N}=\frac{1}{2} \frac{\partial^{2} E}{\partial N^{2}}
$$

where $\mu$ is the chemical potential, $N$ is the number of electrons, and $E$ is the energy. R. G. Pearson proposed [73] the following operational definition for absolute hardness

$$
\eta=\frac{I P-E A}{2}
$$

where IP and EA are ionization energy and electron affinity respectively. According to Koopman's theorem, IP and EA calculated from orbital energies are defined as

$$
I P=-E_{\mathrm{HOMO}}, E A=-E_{\mathrm{LUMO}}
$$


$E_{\mathrm{HOMO}}$ and $E_{\mathrm{LUMO}}$ are the energies of the highest occupied and the lowest unoccupied molecular orbitals. Based on the formula given above, the hardness can be represented as a measure of change resistance of the electron cloud of the chemical system. Softness $(\sigma)$ is defined as the reciprocal of hardness. This is an important parameter for chemical reactions since most reactive species have higher softness value. Electronegativity $(\chi)$ is also defined in terms of energies of HOMO and LUMO as

$$
\chi=\frac{I P+E A}{2}
$$

\section{Results and Discussion}

The results of measuring $E_{\text {corr }}$ of a brass electrode in a neutral chloride solution in the presence of mercaptoalkyl derivatives of 5-amino- $1 \mathrm{H}$-1,2,4-triazole are given in Table 2. In the presence of 3-mercaptopropyl-5-amino- $1 H-1,2,4$-triazole (inhibitor A) with the concentration of $C_{\text {inh }}=0.01 \mathrm{mM}$ the corrosion potential of the electrode decreases slightly. As the concentration of the inhibitor increases up to $0.10-1.00 \mathrm{mM}, E_{\mathrm{corr}}$ shifts noticeably to the anodic region.

Table 2. Open circuit potential $E_{\text {corr, }}$ polarization resistance $R_{\mathrm{p}}$, corrosion current density $i_{\text {corr }}$ and degree of protection of brass $Z_{i}$, in $10 \mathrm{mM} \mathrm{NaCl}$ solutions with various 3-mercaptoalkyl derivatives of 5-amino- $1 H$-1,2,4-triazole.

\begin{tabular}{cccccc}
\hline Inhibitor & $C_{\text {inh }}, \mathbf{m M}$ & $E_{\text {corr }}, \mathbf{V}$ & $R_{\mathbf{p}}, \mathbf{k} \Omega \cdot \mathbf{c m}^{2}$ & $i_{\text {corr }} \mu \mathbf{A} \cdot \mathbf{c m}^{-2}$ & $Z_{i}, \%$ \\
\hline- & - & 0.111 & $1.51 \pm 0.11$ & $26 \pm 4$ & - \\
\hline \multirow{3}{*}{$\mathrm{A}$} & 0.01 & 0.100 & $1.73 \pm 0.10$ & $38 \pm 5$ & -46.2 \\
& 0.10 & 0.200 & $382 \pm 24$ & $0.06 \pm 0.02$ & 99.8 \\
& 1.00 & 0.200 & $244 \pm 18$ & $0.11 \pm 0.03$ & 99.6 \\
\hline \multirow{2}{*}{ B } & 0.01 & 0.110 & $0.76 \pm 0.09$ & $13 \pm 3$ & 50.0 \\
& 0.10 & 0.200 & $195 \pm 13$ & $0.12 \pm 0.04$ & 99.5 \\
& 1.00 & 0.250 & $170 \pm 15$ & $0.19 \pm 0.06$ & 99.3 \\
\hline \multirow{2}{*}{ C } & 0.01 & 0.120 & $20.9 \pm 2.3$ & $4.0 \pm 0.7$ & 84.6 \\
& 0.10 & 0.150 & $143 \pm 18$ & $0.22 \pm 0.05$ & 99.2 \\
& 1.00 & 0.180 & $281 \pm 24$ & $0.12 \pm 0.03$ & 99.5 \\
\hline
\end{tabular}

When 3-mercaptobutyl-5-amino-1H-1,2,4-triazole (inhibitor B) is used with the concentration of $0.01 \mathrm{mM}$, the corrosion potential remains stable. When $C_{\mathrm{inh}} \geq 0.10 \mathrm{mM}$, the potential increases at least by 0.1 V. 3-mercapto(3-methylbutyl)-5-amino-1H-1,2,4-triazole (inhibitor C) added to the chloride solution also results in $E_{\text {corr }}$ shifting to the anodic region, with the shift increasing at higher concentrations of the inhibitor. Thus, the analysis of $E_{\text {corr }}$ demonstrates that the derivatives of 5-amino-1H-1,2,4-triazole can be classified as anodic inhibitors.

The polarization curves of brass in neutral chloride solutions, with the inhibitors under consideration, are given in Figure 1a-c. We can see that when the anodic polarization is low, the current density for all mercaptoalkyl derivatives is lower than in the solution without the inhibitors independent of their concentration. When the concentration of the additive is $0.01 \mathrm{mM}$ (Figure 1a, curve 2), an increase in polarization results in the anodic maximum, while when $C_{\text {inh }} \geq 0.10 \mathrm{mM}$, the polarization curve has no peaks and the anodic current density does not exceed $1 \mathrm{~mA} \cdot \mathrm{cm}^{-2}$. In such solutions, the brass electrode remains passive up to the potential of local activation by chlorides. The potential is much higher than in solutions without the organic additive, and increases at higher concentrations of the inhibitor. 


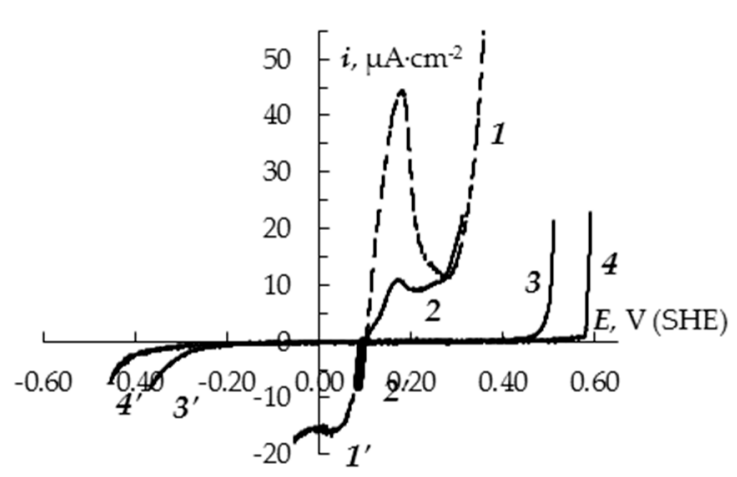

(a)

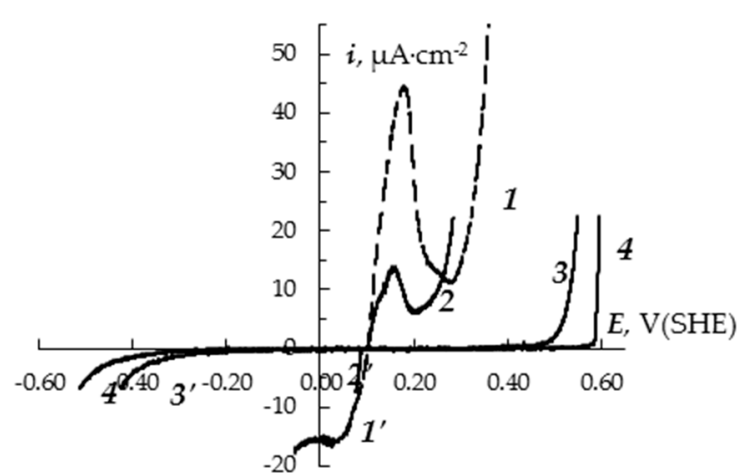

(b)

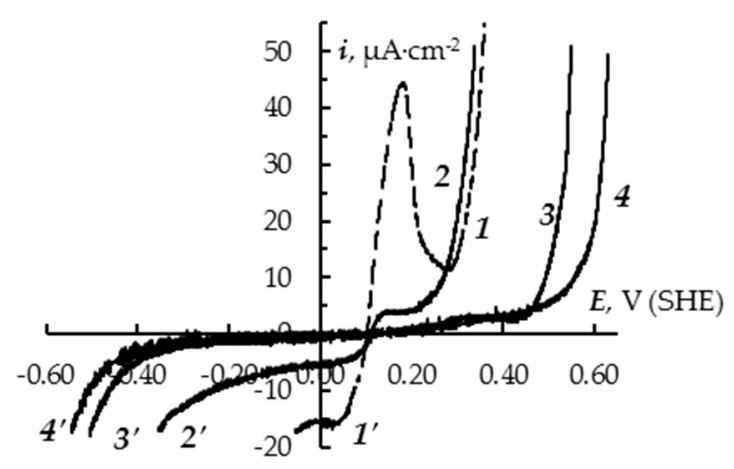

(c)

Figure 1. Anodic (1-4) and cathodic (1'-4') polarization curves of $\alpha$-brass in a borate buffer ( $\mathrm{pH} 7.4$ ) with $0.01 \mathrm{M} \mathrm{NaCl}$ and 3-mercaptopropyl-5-amino-1H-1,2,4-triazole (a), 3-mercaptobutyl-5-amino$1 H$-1,2,4-triazole (b) and 3-mercapto(3-methylbutyl)-5-amino- $1 H$-1,2,4-triazole (c) at the following concentrations: $1,1^{\prime}-0 ; 2,2^{\prime}-0.01 \mathrm{mM} ; 3,3^{\prime}-0.10 \mathrm{mM} ; 4,4^{\prime}-1.00 \mathrm{mM}$.

The difference between cathodic curves of brasses in solutions with, and without, inhibitors becomes noticeable only when $C_{\text {inh }} \geq 0.10 \mathrm{mM}$. In fact, cathodic curves obtained without any inhibitors and when their concentration was $0.01 \mathrm{mM}$ are almost identical (Figure 1a-c, curves $1^{\prime}$ and $2^{\prime}$ ). The higher the concentration of the inhibitor, the lower the current density (Figure 1a-c, curves $3^{\prime}$ and $\left.4^{\prime}\right)$. This means that the cathodic process is slowing down. The region of the rapid growth of the cathodic current density is shifted towards negative values by at least $0.3 \mathrm{~V}$ as compared to that of the chloride solution without inhibitors.

Analysis of the polarization resistance $R_{\mathrm{p}}$, the rate of corrosion, and the protection level (Table 2) demonstrate that the protective effect of all the studied 3-mercaptoalkyl derivatives of 5-amino- $1 H$-1,2,4-triazole depends on their concentration and reaches its maximum when $C_{\text {inh }} \geq$ $0.10 \mathrm{mM}$. In the latter case $R_{\mathrm{p}}$ increases by over 100 times and the corrosion rate deteriorates correspondingly. When the concentration of the additive is $0.01 \mathrm{mM}$, inhibitor A does not demonstrate any protective effect, while inhibitors $B$ and $C$ slow down the rate of corrosion by two, and six times, respectively. Thus, even when the concentration is low, the protective effect of the inhibitor increases as the alkyl chain gets longer.

The same results were obtained during the salt spray testing (Table 3). 
Table 3. Registered time of first corrosion attacks during the salt spray testing $\left(\tau_{\text {corr }}\right.$, hours).

\begin{tabular}{ccccc}
\hline \multirow{2}{*}{ Inhibitor } & \multicolumn{4}{c}{$C_{\mathbf{i n h}}, \mathbf{m M}$} \\
\cline { 2 - 5 } & $\mathbf{0 . 0}$ & $\mathbf{1 . 0}$ & $\mathbf{5 . 0}$ & $\mathbf{1 0 . 0}$ \\
\hline $\mathrm{A}$ & & 68 & 98 & 152 \\
$\mathrm{~B}$ & 3 & 173 & 194 & 212 \\
$\mathrm{C}$ & & 94 & 117 & 283 \\
\hline
\end{tabular}

Indeed, the period when the first signs of corrosion attack appear $\tau_{\text {corr }}$, if $C_{i n h}=10 \mathrm{mM}$, is shorter for inhibitor $\mathrm{A}$, and longer for inhibitors $\mathrm{B}$ and $\mathrm{C}$. With lower $C_{\text {inhh }}$, 3-mercaptobutyl-5-amino-1H-1,2,4-triazole demonstrates the best protective effect. $\tau_{\text {corr }}$ increases with higher $C_{\text {inh }}$, and reaches 6-12 days at $10 \mathrm{mM}$, which proves the effectiveness of 3-mercaptoalkyl derivatives of 5-amino- $1 H$-1,2,4-triazole for $\alpha$-brass in moist atmosphere.

Another proof are the images of the surface of brass samples held in the salt spray cabin (Figure 2). They show that in the presence of the inhibitor the brass electrode remains bright and smooth even if the concentration of the organic additive is minimal. Without the inhibitors, the surface of the electrode darkens, and corrosion spots appear.
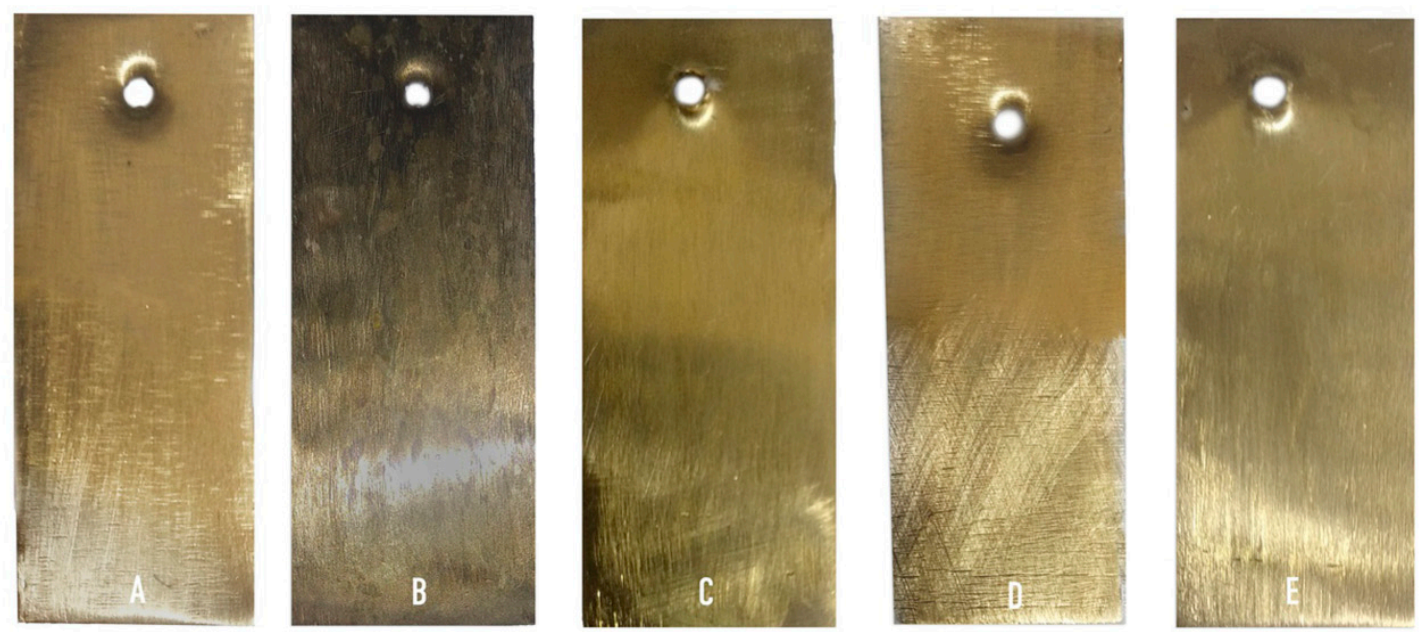

Figure 2. Brass samples before (A) and after salt spray corrosion testing without an inhibitor (B), and in the presence of 3-mercaptobutyl-5-amino-1H-1,2,4-triazole at concentrations of 1 (C), 5 (D), $10 \mathrm{mM}$ (E).

To explain the effect, we carried out scanning electron microscopy and analyzed the micrographs of the brass electrode surface taken before, and after, the potentio-dynamic anodic polarization in a neutral chloride solution (Figure 3). Polarization was performed at intervals from the current-less potential to the activation potential. Figure 3 demonstrates that, without the inhibitors, multiple corrosion spots of about $10 \mu \mathrm{m}$ appear on the surface. However, when the brass is polarized in the solution with $1 \mathrm{mM}$ of 3-mercapto(3-methylbutyl)-5-amino-1H-1,2,4-triazole, no pits can be observed on the surface. The micrographs show only scratches left from polishing the electrode.

The results of the analysis of the elemental composition of the surface layer of the brass electrode before and after anodic polarization are given in Table 4.

It is interesting that anodic polarization does not result in any change in the ratio of the atomic fractions of copper and zinc, which means that there is no dezincification. It is possible that oxides are formed during the anodic oxidation of both components of the alloy. This is also demonstrated by the presence of oxygen. The increase in the oxygen concentration on the brass surface in the presence of the inhibitor is observed because of the formation of a multicomponent passive film, which includes $\mathrm{ZnO} \cdot \mathrm{xH}_{2} \mathrm{O}, \mathrm{Cu}_{2} \mathrm{O}$, and $\mathrm{CuO}$ oxides [5,14-16], together with sparingly soluble complex compounds of zinc and copper with molecules of the studied inhibitors [67-69]. 


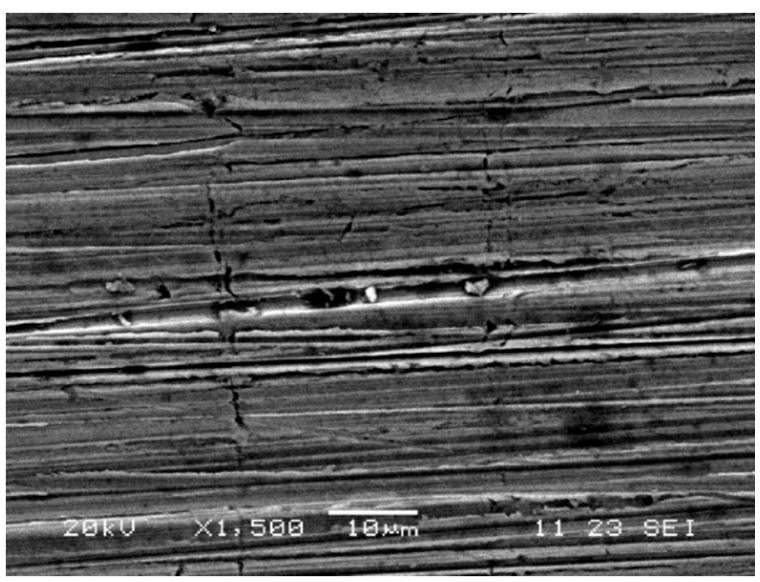

(a)

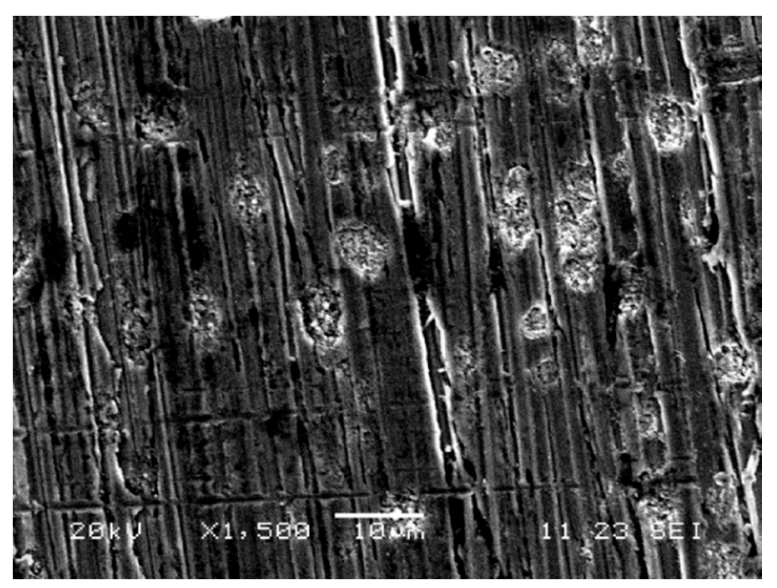

(b)

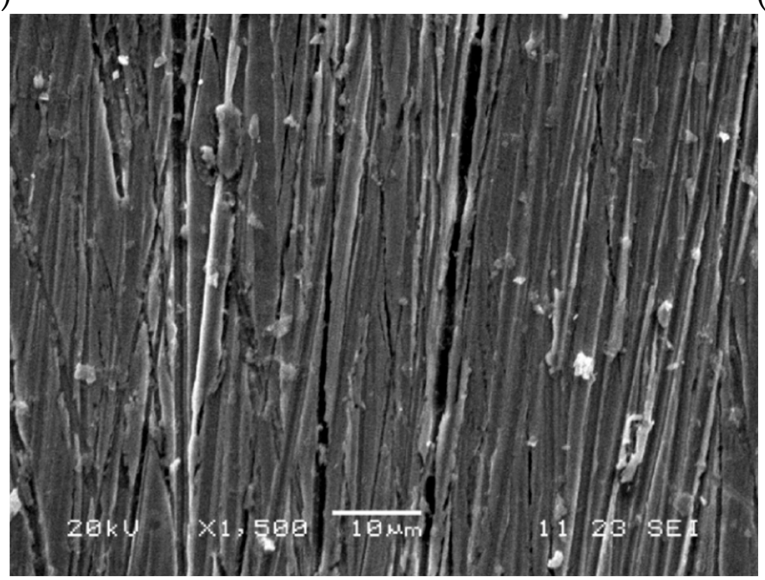

(c)

Figure 3. SEM micrographs of $\alpha$-brass surface (a) before polarization, (b) after polarization in borate buffer (pH 7.4) $+10 \mathrm{mM} \mathrm{NaCl}$, (c) after polarization in borate buffer $(\mathrm{pH} 7.4)+10 \mathrm{mM} \mathrm{NaCl}+1.00 \mathrm{mM}$ of 3-mercapto(3-methylbutyl)-5-amino-1H-1,2,4-triazole (structure B).

Table 4. Elemental surface composition (at. \%) of the brass electrode.

\begin{tabular}{ccccc}
\hline Polarization Mode & \multicolumn{4}{c}{ Element } \\
\cline { 2 - 5 } & $\mathbf{C u}$ & $\mathbf{Z n}$ & $\mathbf{O}$ & $\mathbf{C u} / \mathbf{Z n}$ \\
\hline No polarization & 61.16 & 38.84 & 0.00 & $61 / 39$ \\
After polarization in borate buffer $+10 \mathrm{mM} \mathrm{NaCl}$ & 59.04 & 37.51 & 3.45 & $61 / 39$ \\
$\begin{array}{c}\text { After polarization in borate buffer + } 10 \mathrm{mM} \mathrm{NaCl}+1.00 \mathrm{mM} \\
\text { of 3-mercapto(3-methylbutyl)-5-amino-1H-1,2,4-triazole }\end{array}$ & 57.13 & 35.47 & 7.39 & $62 / 38$ \\
\hline
\end{tabular}

The electrochemical impedance spectroscopy also proves that a protective film forms on brass in neutral chloride solutions with 3-mercaptoalkyl-5-amino-1H-1,2,4-triazoles. Figure 4 presents Nyquist diagrams obtained for the chloride-borate solution with (Figure 4a) and without the A, B, and C inhibitors with concentrations of $C_{\text {inh }}=0.01-1.00 \mathrm{mM}$ (Figure $4 \mathrm{~b}-\mathrm{d}$ ). The hodographs are presented as imperfect semi-circumferences, the imperfection being usually accounted for by the impedance frequency dispersion and the geometric and/or energetic inhomogeneity of the electrode's surface.

We can see that when the organic additives are added to the neutral solution, or when $C_{\text {inh }}$ increases, the shape of the impedance diagram does not change, but the radius of the semi-circumference increases significantly. The regression analysis of the impedance spectroscopy data was used to determine the most probable equivalent circuit simulation the processes at the brass/solution interface (Figure 5). Table 5 presents the values of the following circuit elements: $R_{\Omega}$ (ohmic resistance of the solution), 
$C_{\mathrm{DL}}$ (double-layer capacitance), $R_{\mathrm{p}}$ (polarization resistance of the electrochemical reaction), and $B W$ (Warburg impedance).

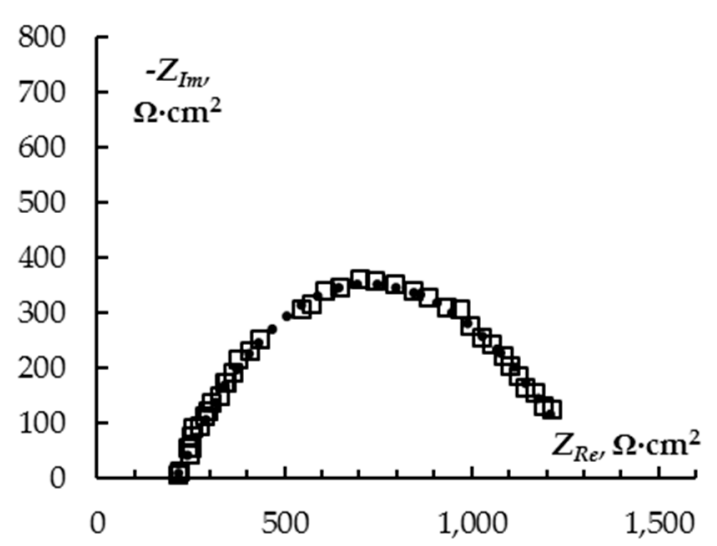

(a)

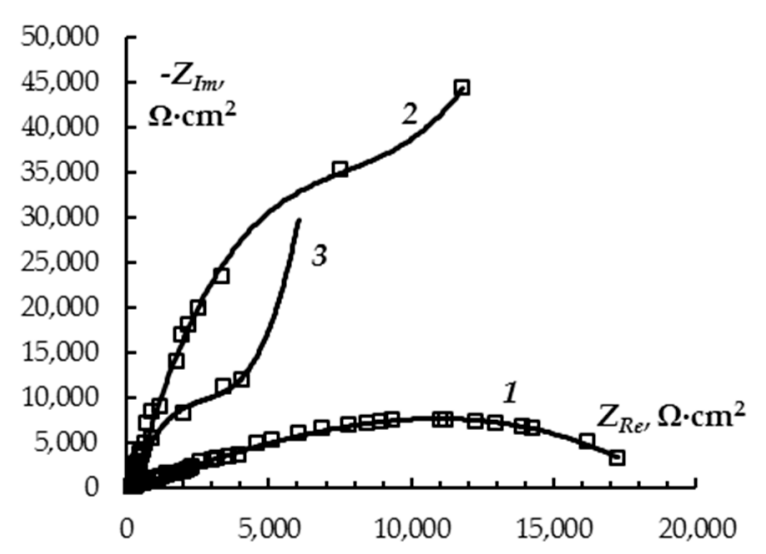

(c)

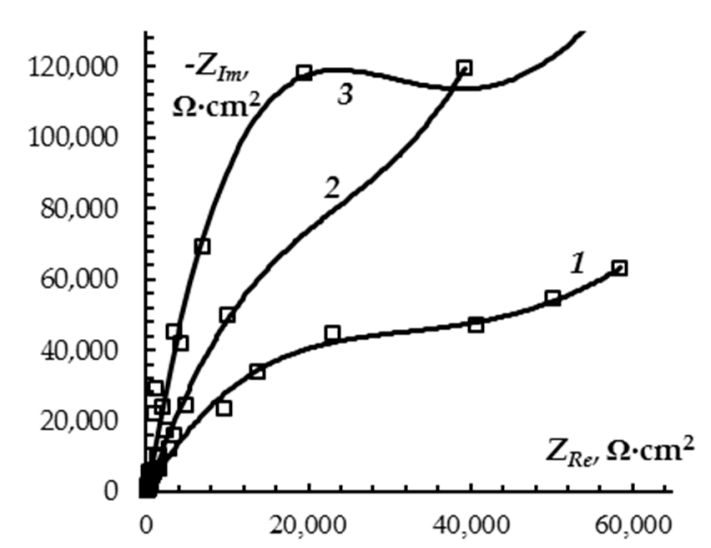

(b)

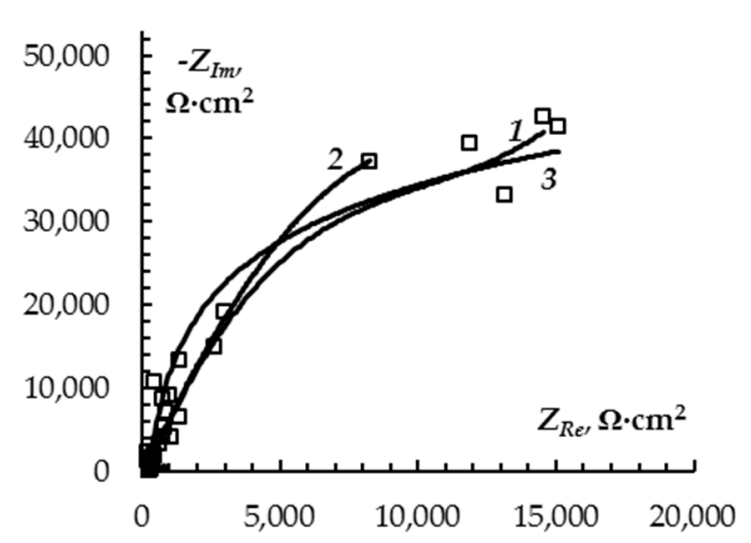

(d)

Figure 4. The Nyquist diagrams of brass in borate buffer $(\mathrm{pH} 7.4)+10 \mathrm{mM} \mathrm{NaCl}$ without an inhibitor (a), in the presence of 3-mercaptopropyl-5-amino-1H-1,2,4-triazole (b), 3-mercaptobutyl-5-amino$1 H$-1,2,4-triazole (c) and 3-mercapto(3-methylbutyl)-5-amino- $1 \mathrm{H}-1,2,4$-triazole (d) at concentrations of $0.01(1), 0.10(2)$, and $1.00 \mathrm{mM}(3)$.

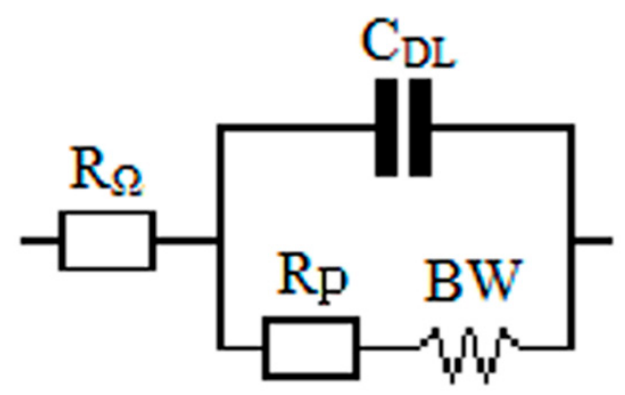

Figure 5. The electric equivalent circuit model used to fit the electrochemical impedance spectroscopy response $\left(R_{\Omega}\right.$-direct-current resistance, $C_{\mathrm{DL}}$-double-layer capacitance, $R_{\mathrm{p}}$-polarization resistance of the electrochemical reaction, $B W$-Warburg impedance). 
Table 5. Equivalent circuit elements and degree of protection of brass electrode in $10 \mathrm{mM} \mathrm{NaCl}$ solutions with various derivatives of 5-amino- $1 H-1,2,4$-triazole.

\begin{tabular}{|c|c|c|c|c|c|c|c|}
\hline \multirow{2}{*}{ Inhibitor } & \multirow{2}{*}{$C_{\mathrm{inh}}, \mathbf{m M}$} & \multirow{2}{*}{$\begin{array}{c}R_{\Omega \prime} \\
\Omega \cdot \mathrm{cm}^{2}\end{array}$} & \multirow{2}{*}{$\begin{array}{c}C_{\mathrm{DL}} \\
\mu \mathrm{F} \cdot \mathrm{cm}^{-2}\end{array}$} & \multirow{2}{*}{$\begin{array}{l}R_{\mathrm{p}}^{\mathrm{EIS}} \\
\mathrm{k} \Omega \cdot \mathrm{cm}^{2}\end{array}$} & \multicolumn{2}{|c|}{$B W, \mathrm{k} \Omega \cdot \mathrm{cm}^{2} \cdot \mathrm{s}^{-0,5}$} & \multirow{2}{*}{$\begin{array}{c}\text { Degree of protection, } \\
\eta_{\text {inh }} \%\end{array}$} \\
\hline & & & & & $B W a$ & $B W b$ & \\
\hline- & 0.00 & 240 & 26.2 & 0.176 & 1.28 & 0.20 & - \\
\hline \multirow{3}{*}{ A } & 0.01 & 256 & 1.57 & 72 & 73 & 1.77 & 99.76 \\
\hline & 0.10 & 250 & 1.00 & 141 & 298 & 6.00 & 99.88 \\
\hline & 1.00 & 258 & 1.54 & 473 & 135 & 0.26 & 99.96 \\
\hline \multirow{3}{*}{ B } & 0.01 & 200 & 2.56 & 0.9 & 13 & 0.81 & 79.86 \\
\hline & 0.10 & 255 & 1.58 & 149 & 151 & 23.27 & 99.88 \\
\hline & 1.00 & 244 & 1.02 & 35 & 9336 & $10^{-6}$ & 99.50 \\
\hline \multirow{3}{*}{$\mathrm{C}$} & 0.01 & 275 & 0.86 & 52 & 239 & 2.87 & 99.66 \\
\hline & 0.10 & 275 & 1.42 & 158 & 20605 & $10^{-6}$ & 99.89 \\
\hline & 1.00 & 275 & 0.79 & 111 & 23526 & $10^{-6}$ & 99.84 \\
\hline
\end{tabular}

$R_{\mathrm{p}}$ is significantly higher in solutions with an organic additive and increases when $C_{\mathrm{inh}}$ is higher, while $C_{D L}$ noticeably decreases. We can thus say that the changes in the hodograph are most probably caused by the decrease in the double-layer capacitance resulting from the adsorption of the inhibitor molecules at the brass/solution interface, on the one hand, and the increase in the polarization resistance resulting from the formation of a protective film on the brass surface, on the other. Further evidence of the formation of the film is that the Warburg impedance grows rapidly in the presence of the inhibitor (Table 5). This means either that the diffusion of the soluble corrosion product on the electrode's surface slows down, or that the barrier properties of the protective film blocking the aggressive elements of the solution increase.

$$
\eta_{\text {inh }}=\left(1-\frac{R_{\mathrm{p}, 0}^{E I S}}{R_{\mathrm{p}, \text { inh }}^{E I S}}\right) \cdot 100 \%
$$

The inhibition effectiveness is calculated using the values of charge transfer resistance without $\left(R_{\mathrm{p}, 0}^{E I S}\right)$ and with the inhibitor $\left(R_{\mathrm{p}, \text { inh }}^{E I S}\right)$, is about $100 \%$ (Table 5) for all the studied inhibitors, when $C_{\mathrm{inh}} \geq$ $0.10 \mathrm{mM}$. This agrees well with the results of the regression analysis of the polarization curves carried out using Mansfeld method (Table 2).

The results of the electrochemical studies and corrosion testing were interpreted within the framework of the quantum chemical approach to the inhibition effect assessment. Optimized molecular structures of 3-mercaptoalkyl-5-amino-1H-1,2,4-triazoles are given in Figure 6. Table 6 gives the values of the ionization potential, electron affinity, electronegativity, absolute hardness and softness in $\mathrm{eV}$ calculated at B3LYP/6-311 + G (d, p), and optimized geometry.

Table 6. Calculated energies of HOMO, LUMO, HOMO LUMO gap (HLG), Ionization Potential $(\mathrm{IP})$, Electron Affinity (EA), Electronegativity $(\chi)$, Absolute Hardness $(\eta)$ and Softness $(\sigma)$ in eV at B3LYP/6-311 + G (d, p) level.

\begin{tabular}{ccccccccc}
\hline Molecule & HOMO & LUMO & HLG & IP & EA & $\chi$ & $\eta$ & $\boldsymbol{\sigma}$ \\
\hline A & -6.36 & -0.61 & 5.75 & 6.36 & 0.61 & 3.49 & 2.88 & 0.35 \\
B & -6.38 & -0.61 & 5.77 & 6.38 & 0.61 & 3.50 & 2.89 & 0.34 \\
C & -6.35 & -0.62 & 5.73 & 6.35 & 0.62 & 3.48 & 2.87 & 0.35 \\
\hline
\end{tabular}

It is known that the ability of inhibitors to interact with a metal surface increases with the growth of HOMO and decrease in LUMO [74]. The smaller the HOMO LUMO gap (HLG), the higher the reactivity of the inhibitor to the metal surface and the stronger the inhibition effect. In Table 6, of all the three triazole molecules, 3-mercapto(3-methylbutyl)5-amino-1H-1,2,4-triazole i.e., molecule C, has the smallest HLG and hardness value of $5.73 \mathrm{eV}$, 
and $2.87 \mathrm{eV}$, respectively. While, 3-mercaptopropyl-5-amino-1H-1,2,4-triazole (molecule A) and 3-mercaptobutyl-5-amino-1H-1,2,4-triazole (molecule B) have the same LUMO energy level of $0.61 \mathrm{eV}$.

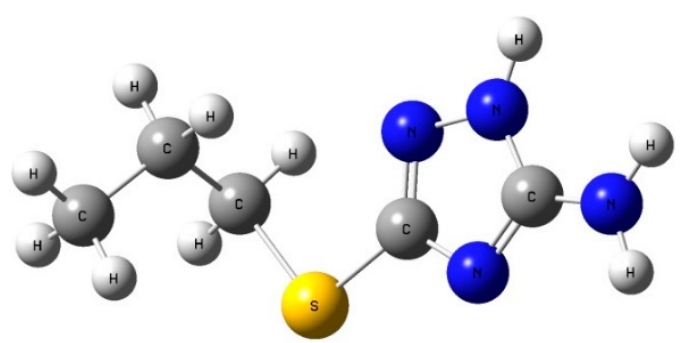

(a)

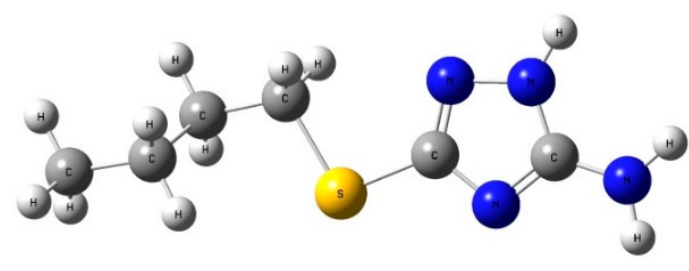

(b)

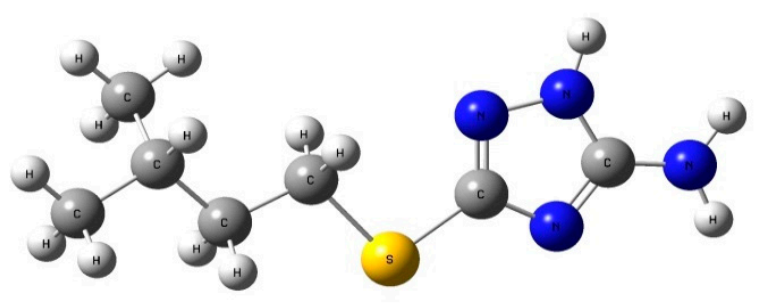

(c)

Figure 6. Optimized structures of the molecules considered for study: 3-mercaptopropyl5-amino-1H-1,2,4-triazole (a), 3-mercaptobutyl-5-amino-1H-1,2,4-triazole (b) and 3-mercapto (3-methylbutyl)-5-amino-1H-1,2,4-triazole (c).

Destabilization of HOMO level $0.02 \mathrm{eV}$ was observed upon changing the substituent from propyl $(A)$ to butyl (B). Of the three molecules, 3-mercaptobutyl-5-amino-1 $H-1,2,4$-triazole (molecule $B$ ) has the largest values of HLG, hardness and electronegativity $-5.77 \mathrm{eV}, 2.89 \mathrm{eV}$, and $3.50 \mathrm{eV}$ respectively. We can, thus, see that the calculated quantum chemical parameters of all the studied molecules of 3-mercaptoalkyl-5-amino- $1 H-1,2,4$-triazoles are very similar. Therefore, their protective effect is also similar, which was proved by testing in neutral chloride solutions when the concentration of the inhibitor was at least $0.10 \mathrm{mM}$.

This section may be divided by subheadings. It should provide a concise and precise description of the experimental results, their interpretation as well as the experimental conclusions that can be drawn.

\section{Conclusions}

The study demonstrates that 3-mercaptoalkyl derivatives of 5-amino- $1 H$-1,2,4-triazole are effective corrosion inhibitors for $\alpha$-brass in chloride environment. Their protective effect increases with the length of the alkyl chain and at higher concentrations of the additive. The maximum protection $(>99 \%)$ is possible at $C_{\text {inh }}>0.10 \mathrm{mM}$, when the inhibitors become comparable in degree of protection. This can be accounted for by the similarity of the quantum chemical parameters of the organic molecules responsible for the inhibition. The inhibition effect results from the formation of a passive film on the brass surface. The film includes oxides of the brass components as well as sparingly soluble complex compounds of zinc and copper with molecules of the considered 3-mercaptoalkyl derivatives of 5-amino- $1 H-1,2,4$-triazole. The fact that the protective film actually forms on the brass surface is proved by a decrease in the double-layer capacitance, an increase in the polarization resistance of the brass electrode, and a rapid increase in the Warburg impedance upon the introduction of the inhibitor.

Author Contributions: Conceptualization, I.Z.; Data curation, Y.K.; Investigation, D.S., A.K., E.K. and A.P.; Methodology, A.K., E.K. and A.P.; Project administration, K.S.; Software, C.P. and A.T.; Writing-original draft, O.K., D.S. and A.K.; Writing-review \& editing, K.S., C.P., A.T., I.Z. and Y.K. 
Funding: The study received financial support from the Ministry of Education and Science of the Russian Federation within the framework of State Contract with universities regarding scientific research in 2017-2019, project No. 4.3633.2017/4.6.

Conflicts of Interest: The authors declare no conflict of interest.

\section{References}

1. Marshakov, I.K. Corrosion resistance and dezincing of brasses. Prot. Met. 2005, 41, 205-210. [CrossRef]

2. Shih, H.C.; Tzou, R.J. Effect of benzotriazole on the stress corrosion cracking and the electrochemical polarization of 70/30 brass in fluoride solutions. J. Electrochem. Soc. 1991, 138, 958-961. [CrossRef]

3. Nishimura, R.; Yoshida, T. Stress corrosion cracking of $\mathrm{Cu}-30 \% \mathrm{Zn}$ alloy in Mattsson's solutions at $\mathrm{pH} 7.0$ and 10.0 using constant load method-A proposal of SCC mechanism. Corros. Sci. 2008, 50, 1205-1213. [CrossRef]

4. El-Mahdy, G.A. Electrochemical impedance study on brass corrosion in $\mathrm{NaCl}$ and $\left(\mathrm{NH}_{4}\right)_{2} \mathrm{SO}_{4}$ solutions during cyclic wet-dry conditions. J. Appl. Electrochem. 2005, 35, 347-353. [CrossRef]

5. Alfantazi, A.M.; Ahmed, T.M.; Tromans, D. Corrosion behavior of copper alloys in chloride media. Mater. Des. 2009, 30, 2425-2430. [CrossRef]

6. Martin, H.; Carro, P.; Hernandez Creus, A.; Morales, J.; Fernandez, G.; Esparza, P.; Gonzales, S.; Salvarezza, R.C.; Arvia, A.J. Inerplay of surface diffusion and surface tension in the evolution of solid/liquid interfaces. Dealloying of $\beta$-brass in aqueous sodium chloride. J. Phys. Chem. B. 2000, 104, 8229-8237. [CrossRef]

7. Zarnitsyn, I.D.; Vvedenskyi, A.V.; Marshakov, I.K. Nonequilibrium behavior of the surface-layer in anodic-dissolution of homogeneous alloys. Russ. J. Electrochem. 1994, 30, 492-512.

8. Polunin, A.V.; Pchelnikov, A.P.; Losev, V.V.; Marshakov, I.K. Electrochemical studies of the kinetics and mechanism of brass dezincification. Electrochim. Acta 1982, 27, 467-475. [CrossRef]

9. Pchelnikova, A.P.; Sitnikov, A.D.; Marshakov, I.K.; Losev, V.V. A study of the kinetics and mechanism of brass dezincification by radiotracer and electrochemical methods. Electrochim. Acta 1981, 26, 591-600. [CrossRef]

10. Zhou, P.; Hutchison, M.J.; Erning, J.W.; Scully, J.R.; Ogle, K. An in situ kinetic study of brass dezincification and corrosion. Electrochim. Acta 2017, 229, 141-154. [CrossRef]

11. Holliday, J.E.; Pickering, H.W.; Holliday, J.E.; Pickering, H.W. A Soft X-Ray Study of the Near Surface Composition of Cu30Zn Alloy during Simultaneous Dissolution of Its Components. J. Electrochem. Soc. 1973, 120, 470-475. [CrossRef]

12. Valcarce, M.B.; de Sanchez, S.R.; Vazquez, M. Brass dezincification in a tap water bacterial suspension. Electrochim. Acta 2006, 51, 3736-3742. [CrossRef]

13. Valcarce, M.B.; de Sanchez, S.R.; Vazquez, M. A comparative analysis of copper and brass surface films in contact with tap water. J. Mater. Sci. 2006, 41, 1999-2007. [CrossRef]

14. Morales, J.; Fernandez, G.T.; Esparza, P.; Gonzalez, S.; Salvarezza, R.C.; Arvia, A.J. A comparative study on the passivation and localized corrosion of $\alpha, \beta$, and $\alpha+\beta$ brass in borate buffer solutions containing sodium chloride-I. Electrochemical data. Corros. Sci. 1995, 37, 211-229. [CrossRef]

15. Morales, J.; Esparza, P.; Fernandez, G.T.; Esparza, P.; Gonzalez, S.; Salvarezza, R.C.; Arvia, A.J. A comparative study on the passivation and localized corrosion of $\alpha$-and $\beta$-brass in borate buffer solutions containing sodium chloride-II. X-ray photoelectron and Auger electron spectroscopy data. Corros. Sci. 1995, 37, 231-239. [CrossRef]

16. Warraky, A.E. Early stages of dezincification of $\alpha$ brass immersed in $4 \% \mathrm{NaCl}$ solution. Br. Corros. J. 1997, 32, 57-62. [CrossRef]

17. Milošev, I.; Mikić, T.K.; Gaberšček, M. The effect of Cu-rich sub-layer on the increased corrosion resistance of $\mathrm{Cu}-x \mathrm{Zn}$ alloys in chloride containing borate buffer. Electrochim. Acta 2006, 52, 415-426. [CrossRef]

18. Ismail, K.M.; El-Egamy, S.S.; Abdelfatah, M. Effects of $\mathrm{Zn}$ and $\mathrm{Pb}$ as alloying elements on the electrochemical behaviour of brass in borate solutions. J. Appl. Electrochem. 2001, 31, 663-670. [CrossRef]

19. El-Rahman, H.A. Passivation and pitting corrosion of $\alpha$-brass $(\mathrm{Cu} / \mathrm{Zn}: 63 / 37)$ in neutral buffer solutions containing chloride ions. Mater. Corros. 1990, 41, 635-639. [CrossRef]

20. Wang, Z.Q.; Gong, Y.L.; Jing, C.; Huang, H.J.; Li, H.R.; Zhang, S.T.; Gao, F. Synthesis of dibenzotriazole derivatives bearing alkylene linkers as corrosion inhibitors for copper in sodium chloride solution: A new thought for the design of organic inhibitors. Corros. Sci. 2016, 113, 64-77. [CrossRef] 
21. Ma, F.B.; Li, W.H.; Tian, H.W.; Hou, B.R. The use of a new thiadiazole derivative as a highly efficient and durable copper inhibitor in 3.5\% NaCl solution. Corros. Sci. 2015, 10, 5862-5879.

22. Gong, Y.L.; Wang, Z.Q.; Gao, F.; Zhang, S.T.; Li, H.R. Synthesis of new benzotriazole derivatives containing carbon chains as the corrosion inhibitors for copper in sodium chloride solution. Ind. Eng. Chem. Res. 2015, 54, 12242-12253. [CrossRef]

23. Finšgar, M. EQCM and XPS analysis of 1,2,4-triazole and 3-amino-1,2,4-triazole as copper corrosion inhibitors in chloride solution. Corros. Sci. 2013, 77, 350-359. [CrossRef]

24. Chirkunov, A.A.; Kuznetsov, Y.I.; Shikhaliev, K.S.; Agafonkina, M.O.; Andreeva, N.P.; Kazansky, L.P.; Potapov, A.Y. Adsorption of 5-alkyl-3-amino-1, 2, 4-triazoles from aqueous solutions and protection of copper from atmospheric corrosion. Corros. Sci. 2018, 144, 230-236. [CrossRef]

25. Bi, H.; Burstein, G.T.; Rodriguez, B.B.; Kawaley, G. Some aspects of the role of inhibitors in the corrosion of copper in tap water as observed by cyclic voltammetry. Corros. Sci. 2016, 102, 510-516. [CrossRef]

26. Qin, T.T.; Li, J.; Luo, H.Q.; Li, M.; Li, N.B. Corrosion inhibition of copper by 2,5-dimercapto-1,3,4-thiadiazole monolayer in acidic solution. Corros. Sci. 2011, 53, 1072-1078. [CrossRef]

27. Sherif, E.M.; El Shamy, A.M.; Ramla, M.M.; El Nazhawy, A.O.H. 5-(Phenyl)-4H-1,2,4-triazole-3-thiol as a corrosion inhibitor for copper in 3.5\% NaCl solutions. Mater. Chem. Phys. 2007, 102, 231-239. [CrossRef]

28. Otmaĉić, H.; Stupnišek-Lisac, E. Copper corrosion inhibitors in near neutral media. Electrochim. Acta 2003, 48, 985-991. [CrossRef]

29. Fan, H.; Li, S.; Zhao, Z.; Wang, H.; Shi, Z.; Zhang, L. Inhibition of brass corrosion in sodium chloride solutions by self-assembled silane films. Corros. Sci. 2011, 53, 4273-4281. [CrossRef]

30. Fouda, A.S.; Ismael, M.A.; Shahba, R.A.; Kamel, L.A.; El-Nagggar, A.A. Corrosion Inhibition of Copper and $\alpha$-Brass in $1 \mathrm{M}$ HNO3 Solution using New arylpyrimido [5, 4-c] quinoline-2, 4-dione derivative. Int. J. Electrochem. Sci. 2017, 12, 3361-3384. [CrossRef]

31. Gao, G.; Liang, C.H. 1, 3-Bis-diethylamino-propan-2-ol as volatile corrosion inhibitor for brass. Corros. Sci. 2007, 49, 3479-3493. [CrossRef]

32. Keleş, H.; Akça, S. The effect of Variamine Blue B on brass corrosion in $\mathrm{NaCl}$ solution. Arabian J. Chem. 2019, 12, 236-248. [CrossRef]

33. Asan, A.; Kabasakaloglu, M.; Işiklan, M.; Kiliç, Z. Corrosion inhibition of brass in presence of terdentate ligands in chloride solution. Corros. Sci. 2005, 47, 1534-1544. [CrossRef]

34. Antonijević, M.M.; Petrović, M.B. Copper corrosion inhibitors. A review. Int. J. Electrochem. Sci. 2008, 3, 1-28.

35. Antonijević, M.M.; Milić, S.M.; Petrović, M.B. Films formed on copper surface in chloride media in the presence of azoles. Corros. Sci. 2009, 51, 1228-1237. [CrossRef]

36. Kuznetsov, Y.I.; Kazansky, L.P. Physicochemical aspects of metal protection by azoles as corrosion inhibitors. Russ. Chem. Rev. 2008, 77, 219-232. [CrossRef]

37. Mihajlović, M.B.P.; Antonijević, M.M. Copper Corrosion Inhibitors. Period 2008-2014. A Review. Int. J. Electrochem. Sci. 2015, 10, 1027-1053.

38. Milošev, I.; Kovačević, N.; Kovač, J.; Kokalj, A. The roles of mercapto, benzene and methyl groups in the corrosion inhibition of imidazoles on copper: I. Experimental characterization. Corros. Sci. 2015, 98, 107-118. [CrossRef]

39. Finšgar, M.; Petovar, B.; Xhanari, K.; Maver, U. The corrosion inhibition of certain azoles on steel in chloride media: Electrochemistry and surface analysis. Corros. Sci. 2016, 111, 370-381. [CrossRef]

40. Kovačević, N.; Milošev, I.; Kokalj, A. How relevant is the adsorption bonding of imidazoles and triazoles for their corrosion inhibition of copper? Corros. Sci. 2017, 124, 25-34. [CrossRef]

41. Allah, A.G.; Badawy, M.W.; Rehan, H.H.; Abou-Romia, M.M. Inhibition of corrosion of $\alpha$-brass (Cu-Zn, 67/33) in acid chloride solutions by some amino pyrazole derivatives. J. Appl. Electrochem. 1989, 19, 928-932. [CrossRef]

42. Walker, R. Triazole, benzotriazole, and naphthotriazole as corrosion inhibitors for brass. Corrosion 1976, 32, $414-417$. [CrossRef]

43. Kosec, T.; Milošev, I.; Pihlar, B. Benzotriazole as an inhibitor of brass corrosion in chloride solution. Appl. Surf. Sci. 2007, 253, 8863-8873. [CrossRef]

44. Kosec, T.; Merl, D.K.; Milošev, I. Impedance and XPS study of benzotriazole films formed on copper, copper-zinc alloys and zinc in chloride solution. Corros. Sci. 2008, 50, 1987-1997. [CrossRef] 
45. Mamaş, S.; Kiyak, T.; Kabasakaloğlu, M.; Koc, A. The effect of benzotriazole on brass corrosion. Mater. Chem. Phys. 2005, 93, 41-47. [CrossRef]

46. Antonijević, M.M.; Milić, S.M.; Šerbula, S.M.; Bogdanović, G.D. The influence of chloride ions and benzotriazole on the corrosion behavior of $\mathrm{Cu} 37 \mathrm{Zn}$ brass in alkaline medium. Electrochim. Acta 2005, 50, 3693-3701. [CrossRef]

47. Ravichandran, R.; Rajendran, N. Influence of benzotriazole derivatives on the dezincification of 65-35 brass in sodium chloride. Appl. Surf. Sci. 2005, 239, 182-192. [CrossRef]

48. Obot, I.B.; Edouk, U.M. Benzimidazole: Small planar molecule with diverse anti-corrosion potentials. J. Mol. Liq. 2017, 246, 66-90. [CrossRef]

49. Ravichandran, R.; Nanjundan, S.; Rajendran, N. Effect of benzotriazole derivatives on the corrosion and dezincification of brass in neutral chloride solution. J. Appl. Electrochem. 2004, 34, 1171-1176. [CrossRef]

50. Ravichandran, R.; Nanjundan, S.; Rajendran, N. Effect of benzotriazole derivatives on the corrosion of brass in $\mathrm{NaCl}$ solutions. Appl. Surf. Sci. 2004, 236, 241-250. [CrossRef]

51. Ravichandran, R.; Rajendran, N. Electrochemical behaviour of brass in artificial seawater: Effect of organic inhibitors. Appl. Surf. Sci. 2005, 241, 449-458. [CrossRef]

52. Stupnišek-Lisac, E.; Gazivoda, A.; Madžarac, M. Evaluation of non-toxic corrosion inhibitors for copper in sulphuric acid. Electrochim. Acta 2002, 47,4189-4194. [CrossRef]

53. Okafor, P.C.; Ikpi, M.E.; Uwah, I.E.; Ebenso, E.E.; Ekpe, U.J.; Umoren, S.A. Inhibitory action of Phyllanthus amarus extracts on the corrosion of mild steel in acidic media. Corros. Sci. 2008, 50, 2310-2317. [CrossRef]

54. Fouda, A.S.; Shalabi, K.; Idress, A.A. Ceratonia siliqua extract as a green corrosion inhibitor for copper and brass in nitric acid solutions. Green Chem. Lett. Rev. 2015, 8, 17-29. [CrossRef]

55. Nagiub, A.; Mansfeld, F. Evaluation of corrosion inhibition of brass in chloride media using EIS and ENA. Corros. Sci. 2001, 43, 2147-2171. [CrossRef]

56. Muñoz, A.I.; Antón, J.G.; Guiñón, J.L.; Herranz, V.P. Comparison of inorganic inhibitors of copper, nickel and copper-nickels in aqueous lithium bromide solution. Electrochim. Acta 2004, 50, 957-966. [CrossRef]

57. Xu, Q.J.; Zhou, G.D.; Wang, H.F.; Cai, W.B. Electrochemical studies of polyaspartic acid and sodium tungstate as corrosion inhibitors for brass and $\mathrm{Cu} 30 \mathrm{Ni}$ alloy in simulated cooled water solutions. Anti-Corros. Met. Mater. 2006, 53, 207-211. [CrossRef]

58. Nihorimbere, M.; Kerroum, Y.; Guenbour, A.; Kacimi, M.; Bellaouchou, A.; Touir, R.; Zarrouk, A. Corrosion inhibition of brass in artificial drinking water by mineral compound. J. Mater. Environ. Sci. 2016, 7, 4121-4128.

59. Abd El-Rahman, H.A. Evaluation of AHT as corrosion inhibitor for $\alpha$-brass in acid chloride solutions. Corrosion 1991, 47, 424-428. [CrossRef]

60. Mountassir, Z.; Srhiri, A. Electrochemical behaviour of $\mathrm{Cu}-40 \mathrm{Zn}$ in $3 \% \mathrm{NaCl}$ solution polluted by sulphides: Effect of aminotriazole. Corros. Sci. 2007, 49, 1350-1361. [CrossRef]

61. Elbakri, M.; Touir, R.; Touhami, M.E.; Srhiri, A.; Benmessaoud, M. Electrosynthesis of adherent poly (3-amino-1,2,4-triazole) films on brass prepared in nonaqueous solvents. Corros. Sci. 2008, 50, 1538-1545. [CrossRef]

62. Finšgar, M. 2-Mercaptobenzimidazole as a copper corrosion inhibitor: Part I. Long-term immersion, 3D-profilometry, and electrochemistry. Corros. Sci. 2013, 72, 82-89. [CrossRef]

63. Finšgar, M. 2-Mercaptobenzimidazole as a copper corrosion inhibitor: Part II. Surface analysis using X-ray photoelectron spectroscopy. Corros. Sci. 2013, 72, 90-98. [CrossRef]

64. Finšgar, M.; Kek Merl, D. 2-Mercaptobenzoxazole as a copper corrosion inhibitor in chloride solution: Electrochemistry, 3D-profilometry, and XPS surface analysis. Corros. Sci. 2013, 80, 82-95. [CrossRef]

65. Finšgar, M.; Merl, D.K. An electrochemical, long-term immersion, and XPS study of 2-mercaptobenzothiazole as a copper corrosion inhibitor in chloride solution. Corros. Sci. 2014, 83, 164-175. [CrossRef]

66. Agafonkina, M.O.; Kuznetsov, Y.I.; Andreeva, N.P.; Shikhaliev, K.S.; Potapov, A.Y. Adsorption and passivation of copper by S-containing heterocyclic compounds in neutral aqueous solutions. Corros. Mater. Prot. 2016, 1, $29-38$.

67. Arkhipushkin, I.A.; Vagramyan, T.A.; Shikhaliev, K.S.; Kazansky, L.P. The study of adsorption of 5-mercaptomethyl-3-amino-1,2,4-triazole on copper in neutral solutions. Corros. Mater. Prot. 2016, 7, 18-24.

68. Arkhipushkin, I.A.; Shikhaliev, K.S.; Potapov, A.Y.; Sapronova, L.V.; Kazansky, L.P. Inhibition of Brass (80/20) by 5-Mercaptopentyl-3-Amino-1,2,4-Triazole in Neutral Solutions. Metals 2017, 7, 488. [CrossRef]

69. Kazansky, L.P.; Pronin, Y.E.; Arkhipushkin, I.A. XPS study of adsorption of 2-mercaptobenzothiazole on a brass surface. Corros. Sci. 2014, 89, 21-29. [CrossRef] 
70. Mansfeld, F. Tafel slopes and corrosion rates obtained in the pre-Tafel region of polarization curves. Corros. Sci. 2005, 47, 3178-3186. [CrossRef]

71. Shih, H.; Mansfeld, F. Software for quantitative analysis of polarization curves. Comput. Model. Corros. ASTM Int. 1992, 174-183. [CrossRef]

72. Frisch, M.J.; Trucks, G.W.; Schlegel, H.B.; Scuseria, G.E.; Robb, M.A.; Cheeseman, J.R.; Scalmani, G.; Barone, V.; Petersson, G.A.; Nakatsuji, H.; et al. Gaussian 16, Revision B.01; Gaussian, Inc.: Wallingford CT, UK, 2016.

73. Parr, R.G.; Pearson, R.G. Absolute hardness: Companion parameter to absolute electronegativity. J. Am. Chem. Soc. 1983, 105, 7512-7516. [CrossRef]

74. Özcan, M.; Dehri, I.; Erbil, M. Organic sulphur-containing compounds as corrosion inhibitors for mild steel in acidic media: Correlation between inhibition efficiency and chemical structure. Appl. Surf. Sci. 2004, 236, 155-164. [CrossRef]

(C) 2019 by the authors. Licensee MDPI, Basel, Switzerland. This article is an open access article distributed under the terms and conditions of the Creative Commons Attribution (CC BY) license (http://creativecommons.org/licenses/by/4.0/). 